\title{
Overexpression of high mobility group box I contributes to progressive clinicopathological features and poor prognosis of human bladder urothelial carcinoma
}

This article was published in the following Dove Press journal:

OncoTargets and Therapy

\section{Changkun Huang* \\ Zhichao Huang* \\ Xiaokun Zhao \\ Yinhuai Wang \\ Hongqing Zhao \\ Zhaohui Zhong \\ Lang Wang}

Department of Urology, The Second Xiangya Hospital, Central South University, Changsha, Hunan,

People's Republic of China

*These authors contributed equally to this work
Correspondence: Lang Wang Department of Urology, The Second Xiangya Hospital, Central South University, No. 139 Renmin Road, Changsha, Hunan 4I00II, People's Republic of China

Tel +86 I37 55I8 I245

Email wanglang@csu.edu.cn
Background: High mobility group box 1 (HMGB1), a versatile protein with intranuclear and extracellular functions, plays an important role in a variety of human cancers. However, the clinical/prognostic significance of HMGB1 expression in human bladder urothelial carcinoma (BUC) remains unclear. The aim of this study was to investigate the HMGB1 expression in human BUC with regard to its clinical and prognostic significance.

Patients and methods: HMGB1 mRNA and protein expressions in tumor and paired normal bladder tissues were detected in $20 \mathrm{BUC}$ cases by quantitative real-time polymerase chain reaction (qRT-PCR) and Western blot. HMGB1 protein expression in 165 primary BUC tissues was evaluated by immunohistochemistry (IHC), and its correlations with clinicopathological characteristics and prognosis were also analyzed. Student's $t$-test, $\chi^{2}$ test, Kaplan-Meier plots, and Cox proportional hazard regression model were performed to analyze the data.

Results: By using qRT-PCR and Western blot, the upregulated expression of HMGB1 mRNA and protein was detected in BUC, compared with paired normal tissue $(P<0.05)$. By using IHC, high HMGB1 expression was examined in 84 of 165 (51.0\%) BUC cases. High HMGB1 expression was significantly correlated with poorer differentiation and higher $\mathrm{T}$ and $\mathrm{N}$ classification (all $P<0.05$ ). Univariate analysis showed that high HMGB1 expression was significantly associated with a shortened patients' overall survival (OS) and disease-free survival (DFS; both $P<0.001$ ). In different subgroups of BUC patients, HMGB1 expression was a prognostic factor in patients with different histological grades or T classification (all $P<0.05$ ), $\mathrm{pN}-$ (both $P<0.001)$ for OS and DFS, and pT1/pN- $(P<0.05)$ for OS. HMGB1 expression, as well as $\mathrm{pT}$ and $\mathrm{pN}$ status, was an independent prognostic factor for both OS $(P=0.001$, hazard ratio $[\mathrm{HR}]=2.973,95 \%$ confidence interval $[\mathrm{CI}]=1.550-5.704)$ and DFS $(P<0.001, \mathrm{HR}=3.019$, $95 \% \mathrm{CI}=1.902-4.792$ ) in multivariate analysis.

Conclusion: Overexpression of HMGB1 may be a new independent molecular marker for the poor prognosis of patients with BUC.

Keywords: high mobility group box 1, bladder urothelial carcinoma, clinicopathology, prognosis

\section{Introduction}

Bladder cancer (BC) is one of the most common and lethal malignancies of the urinary tract worldwide. ${ }^{1}$ Bladder urothelial carcinoma (BUC) is the most common histological type of $\mathrm{BC}$, which represents nearly $90 \%$ of $\mathrm{BCs}$ arising from an epithelial origin. ${ }^{2}$ Based on the degree of tumor infiltration to the muscular bladder wall, BUC is divided 
into non-muscle-invasive BUC (pTa, pTis, and pT1) and muscle-invasive BUC. ${ }^{3}$ Unfortunately, non-muscle-invasive BUC has a high incidence of recurrence and a potential risk of progression to muscle invasion, ${ }^{4,5}$ while the clinical outcome of muscle-invasive BUC is more pessimistic. ${ }^{6}$ So far, the traditional clinicopathological parameters, such as the TNM Classification of Malignant Tumors and histological grade of tumor, can be used as prognostic markers for treatment decisions and predicting the possible clinical outcome. ${ }^{7}$ However, they cannot explain the diverse outcomes of BUC within the same TNM stage and/or histological grade, which result from the heterogeneity of tumor biology. Recently, the advances in genomics have obviously enhanced our knowledge about BC development and elucidated a variety of driver genetic pathways and alterations that are prime targets for individual therapeutic trials that are underway. The research about integrated genomic and protein expression has set the foundation for genomic-based taxonomies anchored in intrinsic molecular subtypes of BC. ${ }^{8-10}$ The diverse heterogeneity of BUC biology has necessitated that patients receive more invasive treatment and intensive follow-up, which has an obvious impact on the quality of afflicted patients' lives and becomes a serious burden of economic expenditure. Thus, it is critical to identify a reliable biomarker to predict the potential prognosis of patients with BUC after surgical resection.

High mobility group box 1 (HMGB1), a highly conserved and evolutionarily ancient protein, is a nonhistone nuclear protein that binds DNA in chromatin structure and expresses in almost all eukaryotic cells. ${ }^{11}$ Within the nucleus, the function of HMGB1 is not only to stabilize nucleosomes by means of binding to the minor groove of DNA, which facilitates the binding of several transcriptional protein assemblies on specific DNA targets, such as p53, p73, nuclear factor- $\kappa \mathrm{B}$ $(\mathrm{NF}-\kappa \mathrm{B})$, and steroid hormone receptors, but also to facilitate the recognition of DNA damage in the process of mismatch repair. ${ }^{12-16}$ Besides its nuclear role, HMGB1 can be passively released from necrotic cells and actively secreted by inflammatory cells, such as mature dendritic cells, neutrophils, macrophages, and natural killer cells, acting as an extracellular damage-associated molecular pattern (DAMP) molecule that binds with several surface receptors, including receptor for advanced glycation end products (RAGE) as well as Toll-like receptor (TLR)-2, TLR-4, and TLR-9 to mediate late systemic inflammation, cell differentiation, cell migration, and tumor progression. ${ }^{17,18}$ In addition, high HMGB1 expression has been detected in many kinds of tumor and predicted a poor prognosis. ${ }^{19-21}$
However, the correlations between the expression dynamics of HMGB1 and its clinicopathological and prognostic significance in human BUC are not very clear. In the present study, the HMGB1 expression in BUC was evaluated by using quantitative real-time polymerase chain reaction (qRT-PCR), Western blot, and immunohistochemistry (IHC). Meanwhile, its clinicopathological and prognostic implication in BUC was also investigated.

\section{Patients and Methods \\ Patients and tissue samples}

For qRT-PCR and Western blot analysis, 20 paired fresh BUC and normal bladder tissues adjacent to tumors (at $>2.0 \mathrm{~cm}$ distance from tumor edge) from the consecutive patients with BUC who underwent surgery were collected at the Department of Urology, The Second Xiangya Hospital, Central South University (Changsha, People's Republic of China), between August 2012 and February 2013. Meanwhile, a cohort of 165 formalin-fixed, paraffin-embedded specimens of BUC diagnosed between 2005 and 2008 at our department were used for immunohistochemical assay. The criteria for study enrollment were distinctive histological diagnosis of BUC; undergoing curative resection for tumor without prior general or local chemotherapy, immunotherapy, and radiotherapy; no history of other malignancy; and availability of follow-up data. For the use of the tissue samples and clinical records for research purposes, written informed consent from the patients and the approval of study protocol from the Ethics Committee of the Second Xiangya Hospital were obtained.

Table 1 describes the main clinicopathological characteristics of all patients in detail. In brief, the 165 patients included 129 men and 36 women with a median age of 66 years ( mean \pm standard deviation $[\mathrm{SD}]=64.9 \pm 12.2$, range $=20-88$ ). The median follow-up time for overall survival (OS) was 70.0 months (mean $\pm \mathrm{SD}=66.9 \pm 19.9$, range $=6.0-110.0$ ) for patients at the time of analysis. Of these, 69 patients underwent radical cystectomy, and 96 patients underwent transurethral resection of bladder tumor. The tumor grade and stage of each patient were classified or reclassified according to the World Health Organization 1973 criteria for grade and the 2002 TNM classification system of the American Joint Committee on Cancer.

\section{qRT-PCR}

Total RNA was isolated from the 20 pairs of BUC and normal bladder tissues using TRIzol ${ }^{\mathrm{TM}}$ reagent (Thermo Fisher Scientific, Waltham, MA, USA). RNA was reverse-transcribed 
Table I Correlation between HMGBI expression and clinicopathological characteristics of BUC patients

\begin{tabular}{|c|c|c|c|c|}
\hline \multirow[t]{2}{*}{ Variables } & \multirow[t]{2}{*}{$\mathbf{n}$} & \multicolumn{2}{|c|}{$\begin{array}{l}\text { HMGB I protein } \\
\text { expression }\end{array}$} & \multirow[t]{2}{*}{$P$-value* } \\
\hline & & Low, n (\%) & High, n (\%) & \\
\hline Age (years) & & & & 0.398 \\
\hline$\leq 65^{\#}$ & 78 & $4 \mathrm{I}(52.6)$ & $37(47.4)$ & \\
\hline$>65$ & 87 & $40(46.0)$ & $47(54.0)$ & \\
\hline Gender & & & & 0.902 \\
\hline Male & 129 & $63(48.8)$ & $66(5 \mid .2)$ & \\
\hline Female & 36 & $18(50.0)$ & I8 (50.0) & \\
\hline Tumor multiplicity & & & & 0.579 \\
\hline Unifocal & 86 & $44(5 \mid .2)$ & $42(48.8)$ & \\
\hline Multifocal & 79 & $37(46.8)$ & $42(53.2)$ & \\
\hline Tumor size $(\mathrm{cm})$ & & & & 0.316 \\
\hline$\leq 3.0^{\$}$ & 79 & $42(53.2)$ & 37 (46.8) & \\
\hline$>3.0$ & 86 & $39(45.3)$ & 47 (54.7) & \\
\hline Histological grade & & & & $<0.001$ \\
\hline GI & 58 & $42(72.4)$ & $16(27.6)$ & \\
\hline $\mathrm{G} 2$ & 55 & $25(45.5)$ & $30(54.5)$ & \\
\hline G3 & 52 & 14 (26.9) & $38(73.1)$ & \\
\hline pT classification & & & & 0.001 \\
\hline $\mathrm{pTa} / \mathrm{p} T$ is & 60 & $4 \mathrm{I}(68.3)$ & $19(31.7)$ & \\
\hline pTI & 43 & $19(44.2)$ & $24(55.8)$ & \\
\hline pT2-pT4 & 62 & $21(33.8)$ & $4 I(66.1)$ & \\
\hline pN classification & & & & 0.001 \\
\hline $\mathrm{pN}-$ & $15 \mid$ & $80(53.0)$ & 7I (47.0) & \\
\hline $\mathrm{pN}+$ & 14 & I (7.I) & $13(92.9)$ & \\
\hline
\end{tabular}

Notes: ${ }^{*} \chi^{2}$ test; ${ }^{*}$ mean age; $\$$ mean size.

Abbreviations: BUC, bladder urothelial carcinoma; HMGBI, high mobility group box I.

to cDNA using the RevertAid ${ }^{\mathrm{TM}} \mathrm{H}$ Minus First-Strand cDNA Synthesis Kit (Thermo Fisher Scientific, Vilnius, Lithuania) according to the manufacturer's instructions. The qRT-PCR assay was performed by using SYBR Green PCR Master Mix (Applied Biosystems, Foster City, CA, USA) in a total reaction volume of $25 \mu \mathrm{L}$ on the ABI PRISM 7900HT Sequence Detection System (Applied Biosystems) as follows: denaturation for 5 minutes at $95^{\circ} \mathrm{C}, 40$ cycles each of denaturation for 20 seconds at $94^{\circ} \mathrm{C}$, annealing for 20 seconds at $61^{\circ} \mathrm{C}$, extension for 20 seconds at $72^{\circ} \mathrm{C}$, and final extension for 5 minutes at $72^{\circ} \mathrm{C}$. The specificity of amplified products was determined by melting curve analysis. The relative expression levels of mRNA were calculated with $2^{-\Delta \Delta \mathrm{Ct}}$ method $^{22}$ and expressed as RQ value normalized to $\beta$-actin. The experiments were repeated in triplicate. The primers used in this study were as follows: HMGB1 forward (5'-AGAAGTGCTCAGAGAGGTGGA-3') and reverse (5'-CCTTTGGGAGGGATATAGGTT-3'); $\beta$-actin forward (5'-CATTAAGGAGAAGCTGTGCT-3') and reverse (5'-GTTGAAGGTAGTTTCGTGGA-3').

\section{Western blot}

Total proteins from the 20 pairs of BUC and normal bladder tissues were extracted by using Total Protein Extraction Kit (ProMab Biotechnologies, Inc., Richmond, CA, USA) in accordance with the manufacturer's protocols. The total protein concentration was determined by using Bradford method. Equal amounts of proteins were electrophoretically separated by $12 \%$ sodium dodecyl sulfate-polyacrylamide gel electrophoresis and then electrotransferred to polyvinylidene fluoride membranes (Millipore, Bedford, MA, USA). After being blocked with 5\% nonfat dried milk in PBS at $37^{\circ} \mathrm{C}$ for overnight, the membranes were then incubated at $37^{\circ} \mathrm{C}$ for 2 hours with mouse HMGB1 antibody (Santa Cruz Biotechnology, Santa Cruz, CA, USA; 1:500 dilution) or mouse $\beta$-actin antibody (Santa Cruz Biotechnology; 1:800 dilution). After washing, the membranes were incubated with horseradish peroxidase-conjugated anti-mouse $\operatorname{IgG}(1: 2,000$ dilution) for 1 hour at room temperature and visualized using enhanced chemiluminescence method. Following exposing and scanning the film, the band intensity was analyzed with Gel-Pro Analyzer Software 4.0 (Media Cybernetics, Bethesda, MD, USA) to calculate integral optical density (IOD). The relative levels of HMGB1 protein were represented as the IOD ratio versus $\beta$-actin.

\section{IHC}

Serial sections $(3 \mu \mathrm{m})$ from formalin-fixed, paraffin-embedded material were dewaxed in xylene and rehydrated with ethanol arranged a graded concentration. They were immersed in $0.01 \mathrm{~mol} / \mathrm{L}$ citrate buffer $(\mathrm{pH}=6.0)$ and heated at $100^{\circ} \mathrm{C}$ for 20 minutes; then, endogenous peroxidase activity was blocked by incubating the sections in methanol containing $3 \%$ hydrogen peroxide for 10 minutes. Following pretreatment with $10 \%$ normal goat serum at room temperature for 15 minutes, the sections were incubated with rabbit polyclonal HMGB1 antibody (Abcam, Cambridge, MA, USA; 1:200 dilution) overnight at $4^{\circ} \mathrm{C}$. Subsequently, horseradish peroxidase-conjugated secondary antibody was used to incubate the sections at room temperature for 30 minutes. Finally, the sections were stained with 3,3-diaminobenzidine, counterstained with hematoxylin, dehydrated, and mounted. A negative control was obtained by replacing the primary antibody with PBS. Known immunostaining positive slides were used as positive control.

\section{IHC evaluation}

Each section was evaluated independently by two pathologists. The expression of HMGB1 was scored according 
to the staining intensity and extent. The staining intensity was ranked into four categories: 0 (negative), 1 (weak), 2 (medium), and 3 (strong). Then, the extent of staining was graded into the following five categories: $0(0 \%), 1$ $(1 \%-25 \%), 2(26 \%-50 \%), 3(51 \%-75 \%)$, and $4(76 \%-$ $100 \%$ ), according to the percentages of positive staining areas in relation to the entire tumor-involved area or the entire section of normal bladder tissue. The final staining score for HMGB1 expression was obtained by multiplying the intensity and extent scores (0-7). For the statistical analysis, tumors with a final staining score $\geq 3$ were defined as having HMGB1 high expression and those with a final staining score $<3$ were classified as having low expression. This evaluation standard was described previously by $\mathrm{Wu}$ et al. ${ }^{23}$

\section{Statistical analysis}

Statistical analysis was performed by using SPSS Version 17.0 software for windows (SPSS Inc., Chicago, IL, USA). Comparisons between the two groups were performed by Student's $t$-test for continuous variables and $\chi^{2}$ test for categorical variables. The correlation between HMGB1 expression and clinicopathological variables was assessed by $\chi^{2}$ test. The OS and disease-free survival (DFS) were further tested with univariate and multivariate survival analyses using the Cox proportional hazard regression model. Data are statistically expressed in terms of mean \pm SD and frequencies (the number of cases). Differences resulting in a $P$-value of $<0.05$ were considered statistically significant.

\section{Results \\ Increased HMGBI mRNA and protein expression in BUC tissue}

The expressions of HMGB1 mRNA and protein were evaluated by qRT-PCR and Western blot in all fresh tissues from 20 BUC patients. The qRT-PCR results showed that HMGB1 mRNA expression level was significantly higher in tumor tissue, compared with that in paired normal bladder tissue $(5.1 \pm 2.3$ vs $2.5 \pm 1.4, P<0.001$; Figure 1$)$. Western blot analyses also showed that HMGB1 protein expression was significantly higher, compared with that in paired normal tissue $(0.88 \pm 0.43$ vs $0.45 \pm 0.36, P=0.001$; Figure 1; Table S1).

\section{Expression of HMGBI in BUC samples as determined by IHC}

To further investigate the subcellular location of HMGB1 protein, we performed IHC analysis on a series of 165 BUC tumor samples and the available 30 specimens of normal bladder tissues. Based on the criteria described previously, the high expression of HMGB1 protein was detected in 51.0\% (84 of 165; Table S2) of BUC samples. However, the HMGB1 staining was much weaker in normal tissues. IHC staining
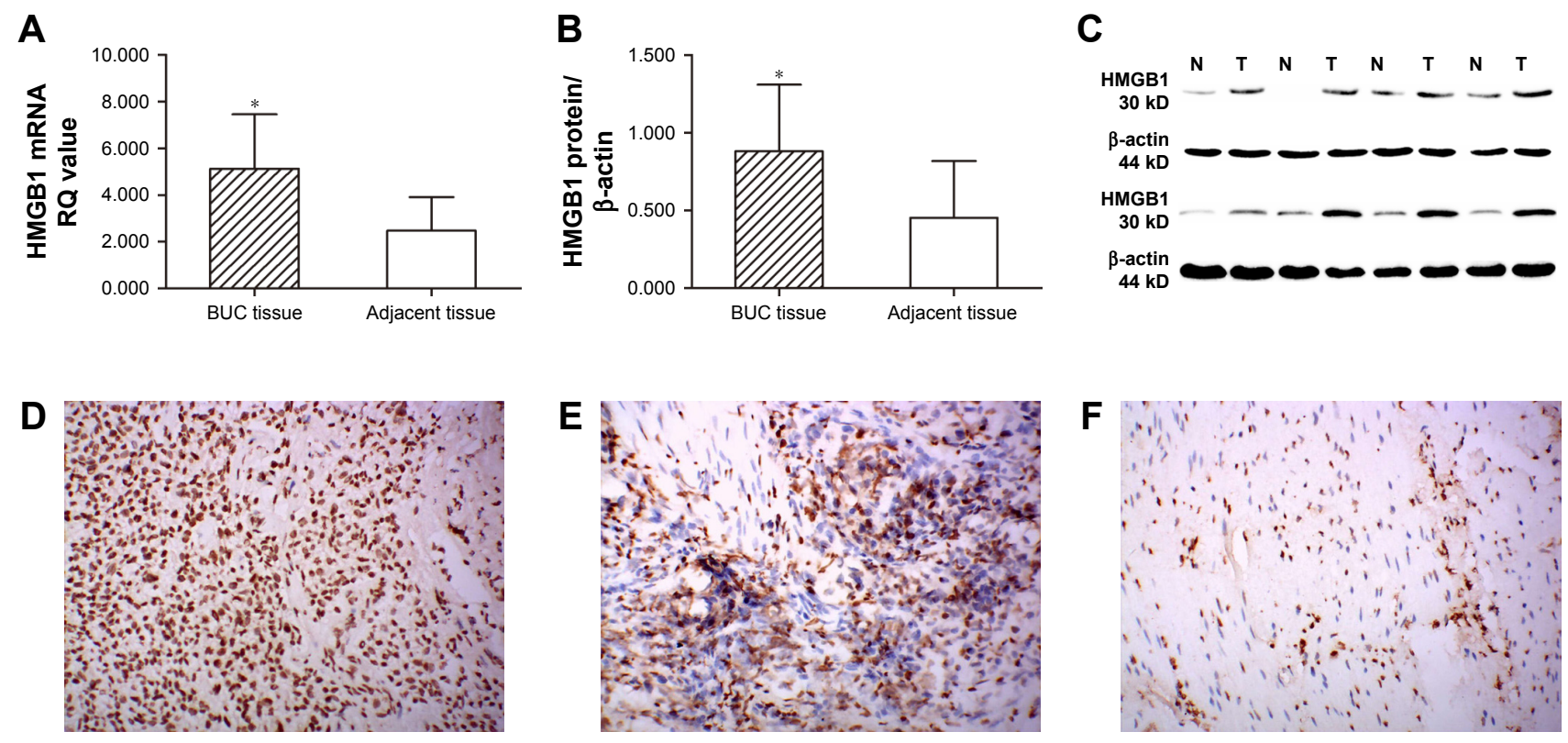

Figure I qRT-PCR was performed to evaluate the levels of HMGBI mRNA in 20 paired fresh BUC and normal bladder tissues adjacent to tumor. Overexpression of HMGBI protein was detected by Western blot in $20 \mathrm{BUCs}$ and paired normal bladder tissues. Expression levels were normalized with $\beta$-actin (T: BUC tissue; $\mathrm{N}$ : paired normal bladder tissue) (A-C). Representative immunohistochemical staining of HMGBI in tumor and normal bladder tissues (original magnification, $\times 200$ ). Extensive expression of HMGBI is found in BUC tissues (D). Low expression of HMGBI is evident in some BUC tissues (E). HMGBI staining is much weaker in the majority of normal bladder tissues (F). $* P<0.05$.

Abbreviations: BUC, bladder urothelial carcinoma; HMGBI, high mobility group box I; qRT-PCR, quantitative real-time polymerase chain reaction. 
showed that the positive staining of HMGB1 was predominantly observed in the nuclei of cells (Figure 1).

\section{Correlation of HMGBI protein expression with BUC patients' clinicopathological variables}

As shown in Table 1, high expression of HMGB1 was significantly correlated with higher T classification $(P=0.001)$, histological grade $(P<0.001)$, and $\mathrm{N}$ classification $(P=0.001)$, respectively. However, no significant difference in HMGB1 protein expression was found with age, gender, tumor multiplicity, and size $(P>0.05)$.

\section{Correlation of HMGBI protein expression, clinicopathological variables, and BUC patients' survival: univariate survival analysis}

In univariate survival analysis, cumulative survival curves of OS and DFS were calculated using Kaplan-Meier method and the differences compared by log rank test (Tables 2 and $\underline{\mathrm{S}}$; Figures 2 and $\underline{\mathrm{S} 1})$. As shown in Table 2, the OS was directly impacted by tumor size $(P=0.018)$, histological grade $(P<0.001)$, T classification $(P<0.001)$, N classification $(P<0.001)$, and the expression of HMGB1 $(P<0.001)$. Furthermore, HMGB1 expression was demonstrated to be a prognostic factor for OS in BUC patients having G1 $(P=0.017), \mathrm{G} 2(P=0.018), \mathrm{G} 3(P=0.03), \mathrm{pTa} / \mathrm{pTis}(P=0.008)$, pT1 $(P=0.001)$, pT2 - pT4 $(P=0.025)$, and pN- $(P<0.001)$, respectively (Table 2; Figure 2 ). In subgroup analysis, high expression of HMGB1 was merely associated with adverse OS of pT1 BUC patients without lymph node metastasis (pT1/pN-, n=41, $P=0.001$; Figure 2).

Similarly, univariate analysis demonstrated that the DFS was significantly influenced by tumor size $(P=0.032)$, histological grade $(P<0.001)$, T classification $(P<0.001)$, $\mathrm{N}$ classification $(P<0.001)$, and the expression of HMGB1 $(P<0.001$; Table 2). Meanwhile, HMGB1 expression was also confirmed as a prognostic factor for DFS in BUC patients having $\mathrm{G} 1(P<0.001), \mathrm{G} 2(P=0.023), \mathrm{G} 3(P<0.001)$, pTa/pTis $(P<0.001)$, pT1 $(P=0.009)$, pT2-pT4 $(P<0.001)$, and $\mathrm{pN}-(P<0.001)$, respectively (Table 2 ; Figure 2$)$.

\section{Multivariate analysis using Cox proportional hazard regression model for independent pronostic factors}

The clinicopathological variables that were significant in univariate analysis, such as tumor size, histological grade,
T classification, N classification, and HMGB1 expression, were further analyzed in multivariate analysis using Cox proportional hazard regression model. The results showed that the expression of HMGB1 was an independent prognostic factor for both OS (hazard ratio $[\mathrm{HR}]=2.973,95 \%$ confidence interval $[\mathrm{CI}]=1.550-5.704, P=0.001$; Table 2) and DFS $(\mathrm{HR}=3.019,95 \% \mathrm{CI}=1.902-4.792, P<0.001$; Table 2). With regard to other variables, histological grade $(\mathrm{HR}=2.556,95 \% \mathrm{CI}=1.705-3.832, P<0.001$, vs $\mathrm{HR}=1.960,95 \% \mathrm{CI}=1.484-2.589, P<0.001)$, $\mathrm{T}$ classification $(\mathrm{HR}=3.108,95 \% \mathrm{CI}=2.023-4.775, P<0.001$, vs $\mathrm{HR}=2.709$, 95\% CI $=2.012-3.646, P<0.001)$, and $\mathrm{N}$ classification $(\mathrm{HR}=3.192,95 \% \mathrm{CI}=1.521-6.700, P=0.002$, vs HR $=2.628$, $95 \% \mathrm{CI}=1.340-5.153, P=0.005)$ were shown to be independent prognostic factors for both OS and DFS (Table 2).

\section{Discussion}

Currently, conventional prognostic evaluation is mainly based on tumor stage and histological grade. ${ }^{9,24}$ However, the clinical outcomes of patients with the same stage and/or grade show substantial variability. ${ }^{8-10}$ Therefore, the inaccurate estimates of survival outcome based on clinicopathological stage and grade may have limited their application as prognostic tools for patient counseling and treatment strategies. Recent studies have suggested that molecular and cellular characteristics of primary tumor lead to the large heterogeneity of prognosis even with the same stage and/or grade. Robertson et al analyzed 412 muscle-invasive bladder cancers characterized by multiple analytical platforms of The Cancer Genome Atlas. In their study, clustering by mRNA, long noncoding RNA, and miRNA expression converged to identify subsets with differential histologic features, carcinoma in situ scores, epithelial-mesenchymal transition status, and survival. Meanwhile, clustering by mutation signature identified a high-mutation subset with 75\% 5-year survival. ${ }^{9}$ Hedegaard et al conducted a multiplatform analysis of nonmuscle-invasive bladder cancer and established two major classes (basal-like and luminal-like) with different clinical characteristics and biological processes. ${ }^{10}$ Thus, there is an urgent need to identify new reliable strategies to effectively and accurately predict patients' prognosis.

HMGB1, a nonhistone DNA-binding protein, is abundantly expressed in almost all eukaryotic cells, and plays dual roles as both a chromatin-associated nuclear protein and an extracellular DAMP molecule. ${ }^{11}$ Within the nucleus, it serves as a structural component to facilitate the assembly of sitespecific DNA-binding protein. ${ }^{13-15}$ In addition to its nuclear role, HMGB1 can be actively secreted by inflammatory cells 
Table 2 Univariate and multivariate analyses of overall and disease-free survival for 165 patients with BUC

\begin{tabular}{|c|c|c|c|c|}
\hline \multirow[t]{2}{*}{ Variables } & \multicolumn{2}{|l|}{ Univariate analysis } & \multicolumn{2}{|c|}{ Multivariate analysis } \\
\hline & HR (95\% Cl) & $P$-value & HR (95\% Cl) & $P$-value \\
\hline \multicolumn{5}{|l|}{ Overall survival } \\
\hline Age (years) & & 0.864 & & \\
\hline$\leq 65^{\#}$ & I & & & \\
\hline$>65$ & $\mathrm{I} .045(0.63 \mathrm{I}-\mathrm{I} .729)$ & & & \\
\hline Gender & & 0.355 & & \\
\hline Male & I & & & \\
\hline Female & $1.318(0.734-2.369)$ & & & \\
\hline Tumor multiplicity & & 0.269 & & \\
\hline Unifocal & I & & & \\
\hline Multifocal & $0.75 I(0.452-1.248)$ & & & \\
\hline Tumor size $(\mathrm{cm})$ & & 0.018 & $1.334(0.756-2.354)$ & 0.319 \\
\hline$\leq 3.0^{\$}$ & I & & & \\
\hline$>3.0$ & $1.872(1.115-3.144)$ & & & \\
\hline Histological grade & & $<0.001$ & $2.556(1.705-3.832)$ & $<0.001$ \\
\hline GI & I & & & \\
\hline $\mathrm{G} 2$ & $18.189(4.312-76.734)$ & & & \\
\hline G3 & $31.785(7.620-132.584)$ & & & \\
\hline PT classification & & $<0.001$ & $3.108(2.023-4.775)$ & $<0.001$ \\
\hline $\mathrm{pTa} / \mathrm{pT}$ is & I & & & \\
\hline pTI & $7.896(2.263-27.550)$ & & & \\
\hline рT2-pT4 & $25.599(7.93 I-82.629)$ & & & \\
\hline pN classification & & $<0.00$ I & $3.192(1.521-6.700)$ & 0.002 \\
\hline $\mathrm{pN}+$ & I & & & \\
\hline $\mathrm{pN}-$ & $7.209(3.732-13.925)$ & & & \\
\hline HMGBI & & $<0.001$ & $2.973(1.550-5.704)$ & 0.001 \\
\hline Low expression & I & & & \\
\hline High expression & $5.102(2.759-9.437)$ & & & \\
\hline \multicolumn{5}{|c|}{ Disease-free survival } \\
\hline Age (years) & & 0.067 & & \\
\hline$\leq 65^{\#}$ & I & & & \\
\hline$>65$ & 1.451 (0.974-2.163) & & & \\
\hline Gender & & 0.555 & & \\
\hline Male & I & & & \\
\hline Female & $0.860(0.522-1.419)$ & & & \\
\hline Tumor multiplicity & & 0.953 & & \\
\hline Unifocal & I & & & \\
\hline Multifocal & $0.988(0.667-1.465)$ & & & \\
\hline Tumor size $(\mathrm{cm})$ & & 0.032 & $1.088(0.709-1.670)$ & 0.701 \\
\hline$\leq 3.0^{\$}$ & I & & & \\
\hline$>3.0$ & I.547 (I.038-2.306) & & & \\
\hline Histological grade & & $<0.001$ & $1.960(1.484-2.589)$ & $<0.001$ \\
\hline GI & I & & & \\
\hline $\mathrm{G} 2$ & $2.267(1.300-3.953)$ & & & \\
\hline G3 & $5.987(3.550-10.098)$ & & & \\
\hline PT classification & & $<0.001$ & $2.709(2.012-3.646)$ & $<0.001$ \\
\hline $\mathrm{pTa} / \mathrm{p} T$ is & I & & & \\
\hline pTI & $\mathrm{I} .896(1.02 \mathrm{I}-3.520)$ & & & \\
\hline pT2-pT4 & $8.318(4.893-|4.14|)$ & & & \\
\hline pN classification & & $<0.001$ & $2.628(1.340-5.153)$ & 0.005 \\
\hline $\mathrm{pN}+$ & 1 & & & \\
\hline $\mathrm{pN}-$ & $5.006(2.738-9.15 I)$ & & & \\
\hline HMGBI & & $<0.001$ & $3.019(1.902-4.792)$ & $<0.001$ \\
\hline Low expression & I & & & \\
\hline High expression & $4.303(2.772-6.680)$ & & & \\
\hline
\end{tabular}

Notes: ${ }^{\#}$ Mean age; ${ }^{\$}$ mean size.

Abbreviations: BUC, bladder urothelial carcinoma; $\mathrm{Cl}$, confidence interval; $\mathrm{HMGBI}$, high mobility group box I; HR, hazard ratio. 
and passively released from necrotic cells into extracellular milieu, acting as an extracellular signaling molecule and binding with high affinity to some receptors, including RAGE as well as TLR-2, TLR-4, and TLR-9 during inflammation, cell differentiation, cell migration, and tumorigenesis. ${ }^{17,18}$ Overexpression of HMGB1 has been reported in a variety of human cancers, such as prostate cancer, renal cell carcinoma (RCC), hepatocellular carcinoma (HCC), lung cancer,
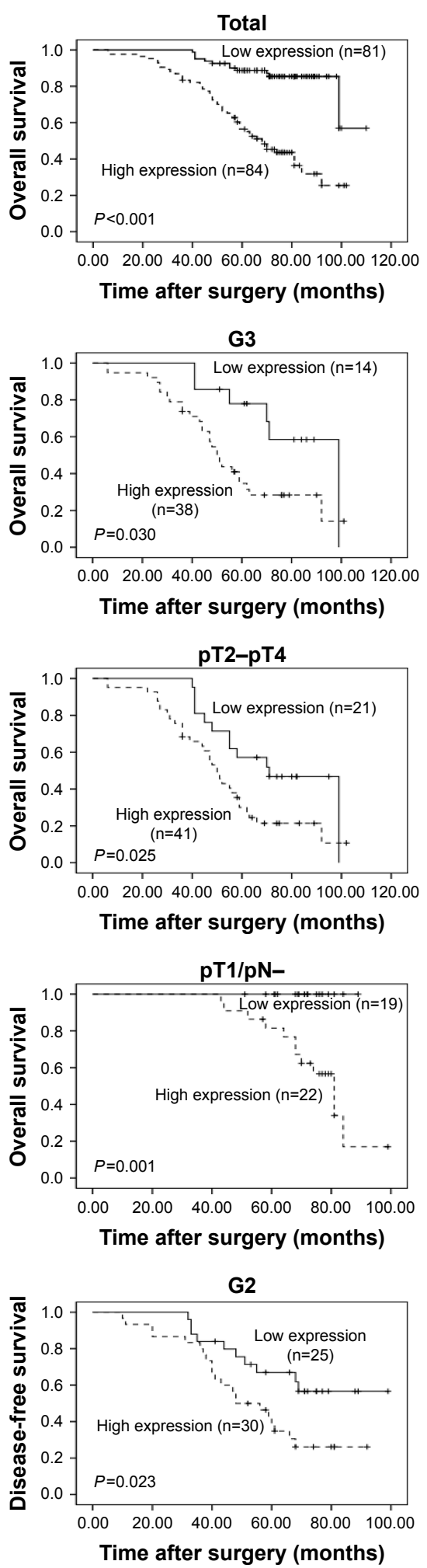

Figure 2 (Continued)
G1
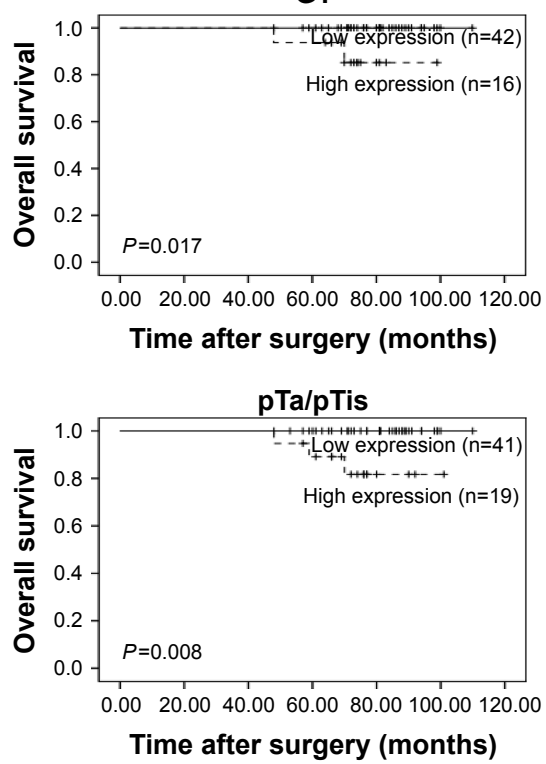

pN-
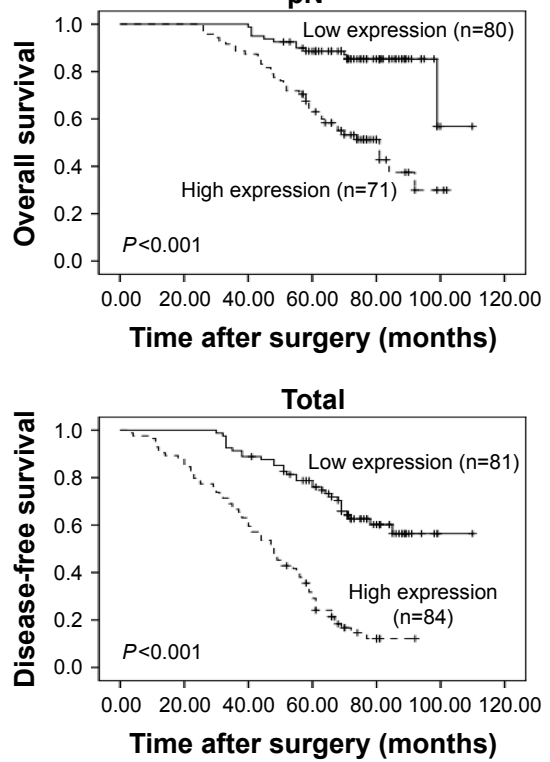

G3

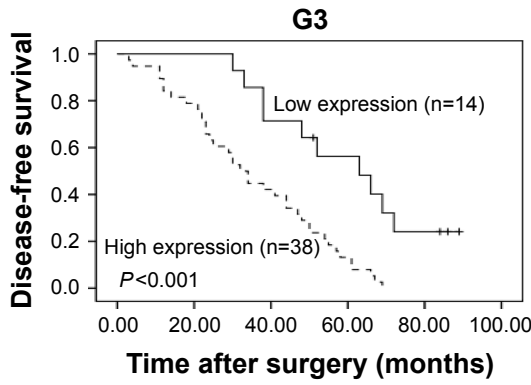

G2

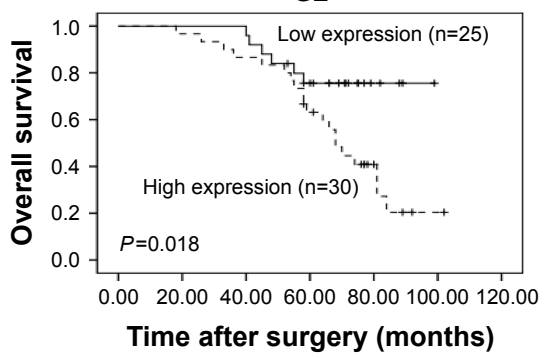

pT1

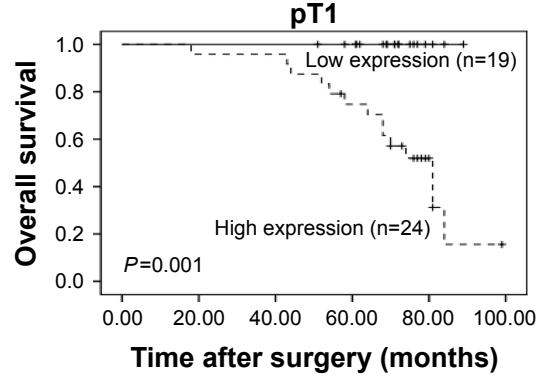

pN+

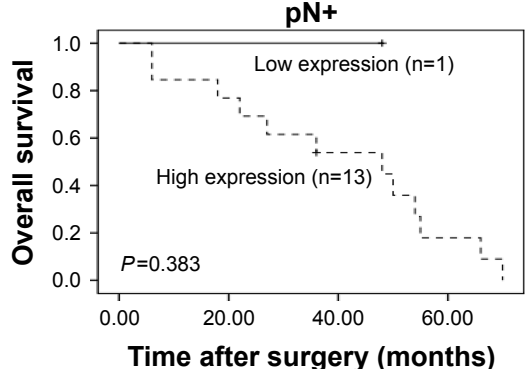

G1

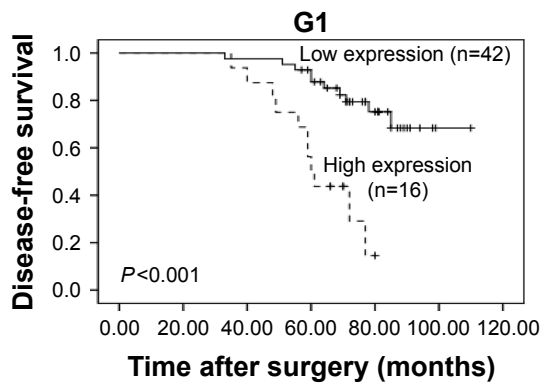

pTa/pTis

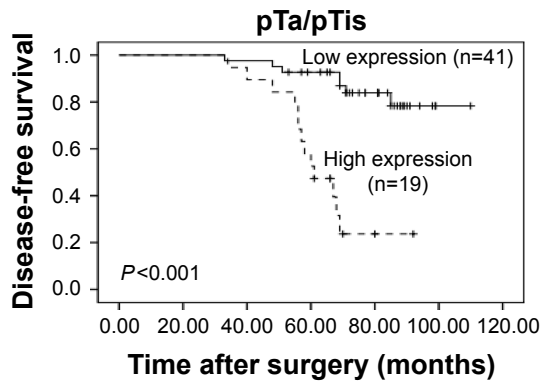



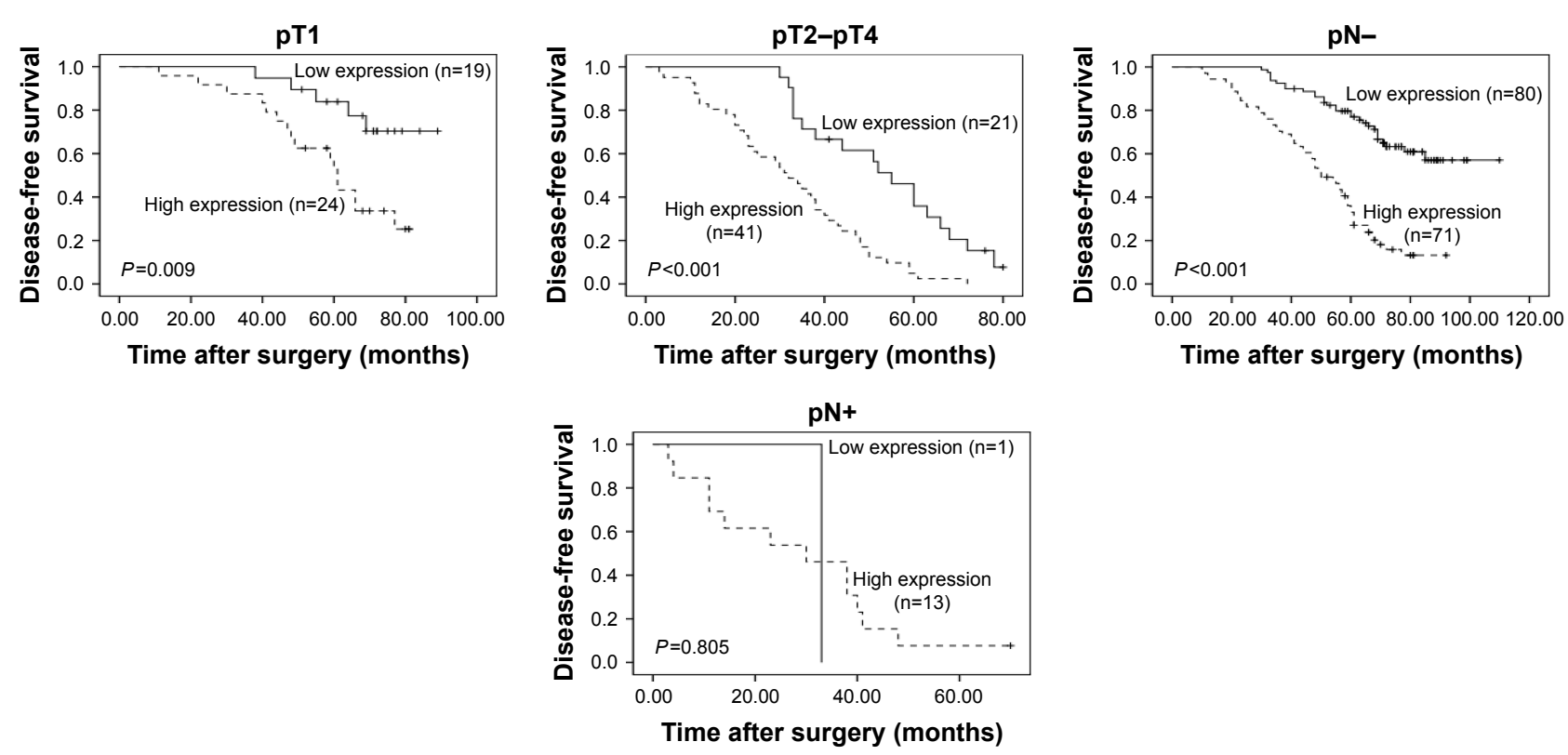

Figure 2 Kaplan-Meier survival analysis of HMGBI expression in 165 BUC patients (log rank test). Abbreviations: BUC, bladder urothelial carcinoma; HMGBI, high mobility group box I.

colorectal cancer, and gastric cancer, which may suggest the potential oncogenic role of HMGB1 in various human cancers. ${ }^{20,25-29}$ Similarly, our study first detected the expression of HMGB1, in both mRNA and protein levels, in BUC and paired normal bladder tissues by qRT-PCR and Western blot, respectively. The results revealed that HMGB1 was overexpressed in BUC tissue compared with the paired normal tissue in both mRNA and protein levels. Meanwhile, the expression dynamics of HMGB1 protein was evaluated by IHC in a cohort of consecutive 165 previous untreated BUC patients and 30 normal bladder tissues. The results not only confirmed the similar pattern of HMGB1 mRNA and protein expression, but also showed that the positive immunostaining of HMGB1 protein was predominantly observed in the nuclei, which coincided with its function as a nuclear protein. These findings are consistent with the findings of previous studies in other human cancers. ${ }^{23,25,29-31}$

Many previous studies have demonstrated that elevated HMGB1 expression is closely associated with more aggressive clinicopathological variables and poorer prognosis in many human cancers. ${ }^{19-21,23,32} \mathrm{Li}$ et al analyzed 168 primary prostatectomy tissue samples using IHC and tissue microarray technique. ${ }^{32}$ Positive expression of HMGB1 was observed in $60.1 \%$ (101 of 168) of the cases, and the expression of HMGB1 was correlated with $\mathrm{T}$ stage $(P=0.011)$, Gleason score, preoperative prostate-specific antigen concentration, and biochemical recurrence (BCR), respectively $(P<0.001)$. Univariate and multivariate survival analyses showed that prostate cancer patients who underwent radical prostatectomy
(RP) with positive HMGB1 expression had a poorer BCRfree survival rate at 5 years $(6.0 \%$ vs $54.0 \%, P<0.001)$, and HMGB1 expression was an independent prognostic factor for BCR-free survival after RP (HR $=2.348,95 \%$ $\mathrm{CI}=1.373-6.361, P=0.001)$. Liu et al evaluated 11 paired fresh HCC, para-tumor, and normal tissues using reverse transcription PCR and Western blot. ${ }^{21}$ The results showed that the levels of HMGB1 mRNA and protein were significantly higher in HCC compared with para-tumor $(P<0.001)$ and normal tissues $(P<0.001)$. In addition, their study also demonstrated that high HMGB1 expression was significantly associated with advanced TNM stage and incomplete tumor encapsulation. Furthermore, the multivariate analysis revealed that high expression of HMGB1 predicted poorer OS and DFS for patients with HCC after curative hepatectomy. In the present study, we further demonstrated that high HMGB1 expression was significantly associated with not only histological grade, but also $\mathrm{T}$ and $\mathrm{N}$ classification. Importantly, HMGB 1 was inversely correlated with OS and DFS of BUC patients, as demonstrated by the Kaplan-Meier curves and Cox proportional hazard regression analysis. Thus, HMGB1 may serve as a potential biomarker to estimate the risk of BUC progression and indicate clinical outcomes after surgical resection, and it may be very useful in optimizing individual BUC therapy strategies.

Overexpression of HMGB1 has been implicated in all central hallmarks of cancer, including apoptosis, angiogenesis, invasion, metastasis, and inflammatory microenvironment. ${ }^{11}$ Our findings indicated the potentially crucial role of HMGB1 
in the biological mechanism involved in tumorigenesis and tumor progression. Knockdown of HMGB1 expression by lentivirus-mediated short hairpin RNA in nude mice could significantly inhibit the growth of subcutaneous tumor and lung metastasis. ${ }^{33}$ Moreover, HMGB1 could regulate the expression of vascular endothelial growth factor $\mathrm{C}$ in the development of HCC partly through NF- $\mathrm{KB}$ signaling pathway, which indicated its potential roles in angiogenesis and lymphangiogenesis of HCC. ${ }^{34,35}$ Furthermore, HMGB1 could stimulate caspase- 1 activation with a series of multiple inflammatory mediators via RAGE and TLR-4 signaling pathways, which led to HCC invasion and metastasis. ${ }^{36}$ Meanwhile, HMGB1 binding to RAGE initiated MEK/ERK signaling pathway, which, in turn, promoted gene expression, protein synthesis, growth, migration, and invasion of RCC. ${ }^{26} \mathrm{HMGB} 1$ is also considered as a marker of necrotic cell death. Previous study has demonstrated HMGB1 release by the BUC cell lines in response to Bacillus CalmetteGuerin (BCG). The level of HMGB1 release significantly correlated with BCG dose and exposure time in T24 and 253J cell lines. ${ }^{37}$ Although our study revealed some associations between HMGB1 expression and prognosis of BUC, the precise mechanisms of HMGB1 involved in oncogenic processes of BUC still requires further study in vitro and in vivo.

\section{Conclusion}

Our study revealed, for the first time, the overexpression of HMGB1 mRNA and protein in human BUC fresh tissue. High expression of HMGB1 was significantly correlated with aggressive clinicopathological variables and poor prognosis of patients with BUC. Furthermore, HMGB1 is an independent prognostic factor for both OS and DFS in BUC patients after surgical resection. Thus, our findings suggested that HMGB1 may serve as a new crucial biomarker to predict clinical outcomes and optimize individual therapy strategy for BUC patients undergoing surgical resection.

\section{Acknowledgment}

The authors are grateful for the invaluable support from the other members of the Department of Urology, The Second Xiangya Hospital, Central South University, Changsha, Hunan, People's Republic of China.

\section{Disclosure}

The authors report no conflicts of interest in this work.

\section{References}

1. Siegel RL, Miller KD, Jemal A. Cancer statistics, 2017. CA Cancer J Clin. 2017;67(1):7-30.
2. Geng J, Fan J, Ouyang Q, et al. Loss of PPM1A expression enhances invasion and the epithelial-to-mesenchymal transition in bladder cancer by activating the TGF-beta/Smad signaling pathway. Oncotarget. 2014; 5(14):5700-5711.

3. Babjuk M, Burger M, Zigeuner R, et al. EAU guidelines on non-muscleinvasive urothelial carcinoma of the bladder: update 2013. Eur Urol. 2013;64(4):639-653.

4. Parekh DJ, Bochner BH, Dalbagni G. Superficial and muscle-invasive bladder cancer: principles of management for outcomes assessments. J Clin Oncol. 2006;24(35):5519-5527.

5. Kaufman DS, Shipley WU, Feldman AS. Bladder cancer. Lancet. 2009; 374(9685):239-249.

6. Malkowicz SB, van Poppel H, Mickisch G, et al. Muscle-invasive urothelial carcinoma of the bladder. Urology. 2007;69(1 Suppl):3-16.

7. VAN Bruwaene S, Costello AJ, VAN Poppel H. Prognosis of nodepositive bladder cancer in 2016. Minerva Urol Nefrol. 2016;68(2): 125-137.

8. Eich ML, Dyrskjot L, Netto GJ. Toward personalized management in bladder cancer: the promise of novel molecular taxonomy. Virchows Arch. Epub 2017 Apr 21.

9. Robertson AG, Kim J, Al-Ahmadie H, et al. Comprehensive molecular characterization of muscle-invasive bladder cancer. Cell. 2017;171(3): 540-556.e525.

10. Hedegaard J, Lamy P, Nordentoft I, et al. Comprehensive transcriptional analysis of early-stage urothelial carcinoma. Cancer Cell. 2016; 30(1):27-42.

11. Guo ZS, Liu Z, Bartlett DL, Tang D, Lotze MT. Life after death: targeting high mobility group box 1 in emergent cancer therapies. Am J Cancer Res. 2013;3(1):1-20.

12. Stros M, Ozaki T, Bacikova A, Kageyama H, Nakagawara A. HMGB1 and HMGB2 cell-specifically down-regulate the p53- and p73dependent sequence-specific transactivation from the human Bax gene promoter. J Biol Chem. 2002;277(9):7157-7164.

13. Brickman JM, Adam M, Ptashne M. Interactions between an HMG-1 protein and members of the Rel family. Proc Natl Acad Sci USA. 1999; 96(19):10679-10683.

14. Onate SA, Prendergast P, Wagner JP, et al. The DNA-bending protein HMG-1 enhances progesterone receptor binding to its target DNA sequences. Mol Cell Biol. 1994;14(5):3376-3391.

15. Imamura $T$, Izumi $H, N a g a t a n i ~ G$, et al. Interaction with $p 53$ enhances binding of cisplatin-modified DNA by high mobility group 1 protein. J Biol Chem. 2001;276(10):7534-7540.

16. Yuan F, Gu L, Guo S, Wang C, Li GM. Evidence for involvement of HMGB1 protein in human DNA mismatch repair. J Biol Chem. 2004; 279(20):20935-20940.

17. Sims GP, Rowe DC, Rietdijk ST, Herbst R, Coyle AJ. HMGB1 and RAGE in inflammation and cancer. Annu Rev Immunol. 2010;28: 367-388.

18. Ellerman JE, Brown CK, de Vera M, et al. Masquerader: high mobility group box-1 and cancer. Clin Cancer Res. 2007;13(10):2836-2848.

19. Bao G, Qiao Q, Zhao H, He X. Prognostic value of HMGB1 overexpression in resectable gastric adenocarcinomas. World J Surg Oncol. 2010;8:52

20. Yao X, Zhao G, Yang H, Hong X, Bie L, Liu G. Overexpression of highmobility group box 1 correlates with tumor progression and poor prognosis in human colorectal carcinoma. J Cancer Res Clin Oncol. 2010; 136(5):677-684.

21. Liu F, Zhang Y, Peng Z, Gao H, Xu L, Chen M. High expression of high mobility group box 1 (hmgb1) predicts poor prognosis for hepatocellular carcinoma after curative hepatectomy. J Transl Med. 2012; 10:135.

22. Livak KJ, Schmittgen TD. Analysis of relative gene expression data using real-time quantitative PCR and the 2(-Delta Delta C(T)) method. Methods. 2001;25(4):402-408.

23. Wu D, Ding Y, Wang S, Zhang Q, Liu L. Increased expression of high mobility group box 1 (HMGB1) is associated with progression and poor prognosis in human nasopharyngeal carcinoma. J Pathol. 2008; 216(2):167-175 
24. Spiess PE, Agarwal N, Bangs R, et al. Bladder Cancer, Version 5. 2017, NCCN Clinical Practice Guidelines in Oncology. J Natl Compr Canc Netw. 2017;15(10):1240-1267.

25. Ishiguro H, Nakaigawa N, Miyoshi Y, Fujinami K, Kubota Y, Uemura H. Receptor for advanced glycation end products (RAGE) and its ligand, amphoterin are overexpressed and associated with prostate cancer development. Prostate. 2005;64(1):92-100.

26. Lin L, Zhong K, Sun Z, Wu G, Ding G. Receptor for advanced glycation end products (RAGE) partially mediates HMGB1-ERKs activation in clear cell renal cell carcinoma. J Cancer Res Clin Oncol. 2012;138(1):11-22.

27. Jiang W, Wang Z, Li X, Fan X, Duan Y. High-mobility group box 1 is associated with clinicopathologic features in patients with hepatocellular carcinoma. Pathol Oncol Res. 2012;18(2):293-298.

28. Liu PL, Tsai JR, Hwang JJ, et al. High-mobility group box 1-mediated matrix metalloproteinase-9 expression in non-small cell lung cancer contributes to tumor cell invasiveness. Am J Respir Cell Mol Biol. 2010; 43(5):530-538.

29. Akaike H, Kono K, Sugai H, et al. Expression of high mobility group box chromosomal protein-1 (HMGB-1) in gastric cancer. Anticancer Res. 2007;27(1A):449-457.

30. Völp K, Brezniceanu ML, Bösser S, et al. Increased expression of high mobility group box 1 (HMGB1) is associated with an elevated level of the antiapoptotic c-IAP2 protein in human colon carcinomas. Gut. 2006;55(2):234-242.
31. Poser I, Golob M, Buettner R, Bosserhoff AK. Upregulation of HMG1 leads to melanoma inhibitory activity expression in malignant melanoma cells and contributes to their malignancy phenotype. Mol Cell Biol. 2003;23(8):2991-2998.

32. Li T, Gui Y, Yuan T, et al. Overexpression of high mobility group box 1 with poor prognosis in patients after radical prostatectomy. BJU Int. 2012;110(11 Pt C):E1125-E1130.

33. Chen J, Liu X, Zhang J, Zhao Y. Targeting HMGB1 inhibits ovarian cancer growth and metastasis by lentivirus-mediated RNA interference. J Cell Physiol. 2012;227(11):3629-3638.

34. Su JL, Yen CJ, Chen PS, et al. The role of the VEGF-C/VEGFR-3 axis in cancer progression. Br J Cancer. 2007;96(4):541-545.

35. Jiang $\mathrm{W}$, Wang $Z$, Li X, et al. Reduced high-mobility group box 1 expression induced by RNA interference inhibits the bioactivity of hepatocellular carcinoma cell line HCCLM3. Dig Dis Sci. 2012;57(1): 92-98.

36. Yan W, Chang Y, Liang X, et al. High-mobility group box 1 activates caspase-1 and promotes hepatocellular carcinoma invasiveness and metastases. Hepatology. 2012;55(6):1863-1875.

37. Shah G, Zhang G, Chen F, Cao Y, Kalyanaraman B, See WA. The dose-response relationship of bacillus calmette-guerin and urothelial carcinoma cell biology. J Urol. 2016;195(6):1903-1910.
OncoTargets and Therapy

\section{Publish your work in this journal}

OncoTargets and Therapy is an international, peer-reviewed, open access journal focusing on the pathological basis of all cancers, potential targets for therapy and treatment protocols employed to improve the management of cancer patients. The journal also focuses on the impact of management programs and new therapeutic agents and protocols on

\section{Dovepress}

patient perspectives such as quality of life, adherence and satisfaction The manuscript management system is completely online and includes a very quick and fair peer-review system, which is all easy to use. Visit http://www.dovepress.com/testimonials.php to read real quotes from published authors. 